\title{
Review: Magnetic Resonance Spectroscopy Studies of Pediatric Major Depressive Disorder
}

\author{
Douglas G. Kondo, ${ }^{1,2}$ Tracy L. Hellem, ${ }^{1}$ Young-Hoon Sung, ${ }^{1,2}$ Namkug Kim, ${ }^{1}$ \\ Eun-Kee Jeong, ${ }^{3}$ Kristen K. DelMastro, ${ }^{1}$ Xianfeng Shi, ${ }^{1}$ and Perry F. Renshaw ${ }^{1,2}$ \\ ${ }^{1}$ The Brain Institute at the University of Utah, 383 Colorow Drive, Salt Lake City, UT 84108-1201, USA \\ ${ }^{2}$ Department of Psychiatry, University of Utah School of Medicine, 30 N. 1900 E, Salt Lake City, UT 84132, USA \\ ${ }^{3}$ Department of Radiology, University of Utah School of Medicine, 30 N. 1900 E, Salt Lake City, UT 84132, USA
}

Correspondence should be addressed to Tracy L. Hellem, tracy.hellem@hsc.utah.edu

Received 6 May 2010; Accepted 20 August 2010

Academic Editor: Bettina F. Piko

Copyright ( 92011 Douglas G. Kondo et al. This is an open access article distributed under the Creative Commons Attribution License, which permits unrestricted use, distribution, and reproduction in any medium, provided the original work is properly cited.

Introduction. This paper focuses on the application of Magnetic Resonance Spectroscopy (MRS) to the study of Major Depressive Disorder (MDD) in children and adolescents. Method. A literature search using the National Institutes of Health's PubMed database was conducted to identify indexed peer-reviewed MRS studies in pediatric patients with MDD. Results. The literature search yielded 18 articles reporting original MRS data in pediatric MDD. Neurochemical alterations in Choline, Glutamate, and NAcetyl Aspartate are associated with pediatric MDD, suggesting pathophysiologic continuity with adult MDD. Conclusions. The MRS literature in pediatric MDD is modest but growing. In studies that are methodologically comparable, the results have been consistent. Because it offers a noninvasive and repeatable measurement of relevant in vivo brain chemistry, MRS has the potential to provide insights into the pathophysiology of MDD as well as the mediators and moderators of treatment response.

\section{Introduction}

Led by a major research initiative from the U.S. National Institute of Mental Health (NIMH), the hunt is on for biomarkers in psychiatry [1]. A biomarker is a characteristic that is objectively measured and evaluated as an indicator of normal biological processes, pathogenic processes, or pharmacological responses to a therapeutic intervention [2]. The readiness of biological markers to serve as features, risk factors, or diagnostic criteria is of significant concern in the development of the DSM-V [3], and the research agenda for DSM-V emphasizes the need to translate research findings into a new classification for psychiatric disorders $[4,5]$. In psychiatry, biomarkers could be used to detect and assess or to predict the development of psychiatric disorders - and more importantly, biomarkers could be used to inform treatment decisions [6]. It has been argued that the DSM-V should be structured to permit incorporation of well-replicated findings from neuroscience, by creating mechanisms to flexibly evaluate genetic markers or neuroimaging results rather than waiting for publication of the DSM-VI [7]. A consensus has emerged that advances in the assessment, treatment, and prevention of brain disorders are likely to originate from studies based on clinical and translational neuroscience [8].

In the search for these translational tools, neuroimaging is a strong candidate to aid psychiatry in its quest to join the other specialties in medicine in utilizing tests anchored in biology for delivering care and developing new interventions. Advances in child psychiatry neuroimaging have begun to provide a scientific infrastructure for understanding numerous psychiatric disorders $[9,10]$. Because it can define the neural structures and pathways that mediate illness and its progression, imaging has the potential for use in clinical decision making and disease monitoring [11]. Owing to the fact that depression is not associated with gross tissue pathology or with unambiguous animal models for spontaneous and recurrent episodes, the availability of research tools to 
noninvasively assess the brain is critical to elucidating the neurobiology of mood disorders [12]. In addition to the scientific insight they provide, the neuroimaging methods employed in child and adolescent psychiatry are noninvasive and have proven to be safe [13].

Child and adolescent psychiatry investigators have adopted a number of neuroimaging approaches. The purpose of this paper is to review the findings reported using Magnetic Resonance Spectroscopy (MRS) in the study of pediatric Major Depressive Disorder (MDD). As the name suggests, MRS is a procedure that allows measurement of relevant neurochemistry. Its application to the study of MDD is therefore of particular interest, because mood disorders are illnesses of "state" $[14,15]$. If MRS is able to define and validate neurochemical biomarkers, then results of MRS studies may one day be utilized to diagnose mood disorders and to monitor treatment response.

MDD is a significant global health problem, ranking 3rd on the World Health Organization's list of the most common causes of disability worldwide [16]. In the U.S., the National Comorbidity Survey Replication study found that the peak age of onset for mental disorders is 14 years, with MDD most commonly emerging during adolescence $[17,18]$. With an annual incidence of $2 \%$ in children and $4 \%$ to $8 \%$ in adolescents [19], and a cumulative lifetime prevalence of up to $20 \%$ [20], MDD in children is associated with academic failure, social impairment, substance abuse, and suicide attempts [19]. Compared with healthy controls, depressed adults are more likely to have had a depressive episode in adolescence [21]. Adding to the morbidity and mortality experienced by patients and their families, pediatric MDD imposes a substantial economic burden on society [22]. The personal and financial toll is amplified by the fact that only $50 \%$ of patients with MDD are diagnosed before reaching adulthood [23]. Therefore, novel diagnostic and treatment tools for patients in the critical adolescent stage of development are urgently needed [24-27].

The paper begins with a brief description of how MRS data is acquired, the information that is obtained, and how that information differs from the results of other neuroimaging methods. Following a review of MRS studies in pediatric MDD, the paper concludes with suggested directions for further study.

\section{Magnetic Resonance Spectroscopy: A Primer}

In 1946, Felix Bloch at Stanford University and Purcell at the Massachusetts Institute of Technology independently demonstrated the phenomenon of Nuclear Magnetic Resonance (NMR) $[28,29]$. It was known that the nuclei of certain elements, for example, hydrogen $\left({ }^{1} \mathrm{H}\right)$ and phosphorus $\left({ }^{31} \mathrm{P}\right)$, have magnetic properties and spin. Bloch and Purcell showed that nuclei containing an odd number of nucleons (i.e., protons + neutrons) could absorb energy at a specific resonance when placed in a strong magnetic field. Based upon the principles of NMR, magnetic resonance imaging (MRI) was introduced to clinical medicine in the 1970s [30]. The principles of NMR were used to develop magnetic resonance spectroscopy (MRS), which enabled characterization of living tissues based upon their chemical constituents [31]. Whereas MRI depicts the spatial distribution of protons of water, which are transformed into a visual representation of anatomy for interpretation, MRS detects various molecules present at concentrations on the order of $\mathrm{mM}$ (millimolar) [32]. For a review of the scientific principles underlying MRS, the interested reader is referred to the referenced publications [33-36].

The key distinction between MRI and MRS is the type of information the magnetic resonance signal is used to encode. MRI studies create anatomical images whereas MRS provides quantitative biochemical information about the tissue under study. Rather than high-resolution images, MRS data are presented as graphical spectra, with the area under each peak representing the relative concentration of nuclei detected for a given atomic species, for example, hydrogen or phosphorus. The $x$-axis of graphed MRS data denotes the frequency shift localizing the metabolite in parts per million. MRS spectra peaks correspond with specific chemical compounds of interest. Thus, MRS non-invasively provides a repeatable measure of chemical concentration data in living tissues, including the human brain. For the patient, the procedure is identical to a clinical study except for the amount of time spent in the scanner; the duration ranges from less than 10 minutes for acquisition of proton spectra to approximately 30 minutes for a phosphorus scan. MRS scans use no radiation, which allows for repeated measurement at different times in the course of a patient's illness, for example, prior to the start of treatment and at the point that remission is achieved. Figure 1 shows an example of ${ }^{1} \mathrm{H}$-MRS spectrum obtained from the anterior cingulate cortex of a patient with MDD.

The chemicals quantifiable with ${ }^{1} \mathrm{H}$-MRS include the following: N-Acetyl-Aspartate (NAA), creatine (Cr), choline (Cho), myoinositol (mI), and lactate (Lac). The term "GLX" (Glx) is used to designate the single peak containing the amino acid neurotransmitters Glutamate (Glu), GammaAminobutyric Acid (GABA), and Glutamine (Gln) [37], because ${ }^{1} \mathrm{H}$-MRS signals from Glu and Gln are complicated by the interaction of neighboring protons and the $\mathrm{pH}$ dependence of chemical shift [38]. Glu is the major excitatory neurotransmitter in the human brain and was first measured in 1992 [39]. Brain in vivo concentrations of Glu are approximately 8-13 times that of GABA, and the ratio of Glu/Gln ranges from 2.4-3.8; therefore, alterations in Glx are typically attributed to altered Glu concentrations [40]. GABA, the major inhibitory neurotransmitter in the brain, has an ${ }^{1} \mathrm{H}$-MRS peak that can be separated from Glx at magnetic field strengths $\geq 2$ Tesla using spectral editing technique or 2-D J-resolved spectra [41].

NAA is the most prominent ${ }^{1} \mathrm{H}$-MRS peak and is found only in the nervous system [42]. It is a marker of neuronal density or function, osmoregulation, and energy homeostasis; there is a direct relationship between NAA synthesis, oxygen consumption, and ATP production in the central nervous system [43]. NAA may also play a critical role in myelin production within oligodendrocytes [44]. Reduction in NAA levels measured by ${ }^{1} \mathrm{H}$-MRS is a recognized marker of neuronal loss or dysfunction in several psychiatric and 


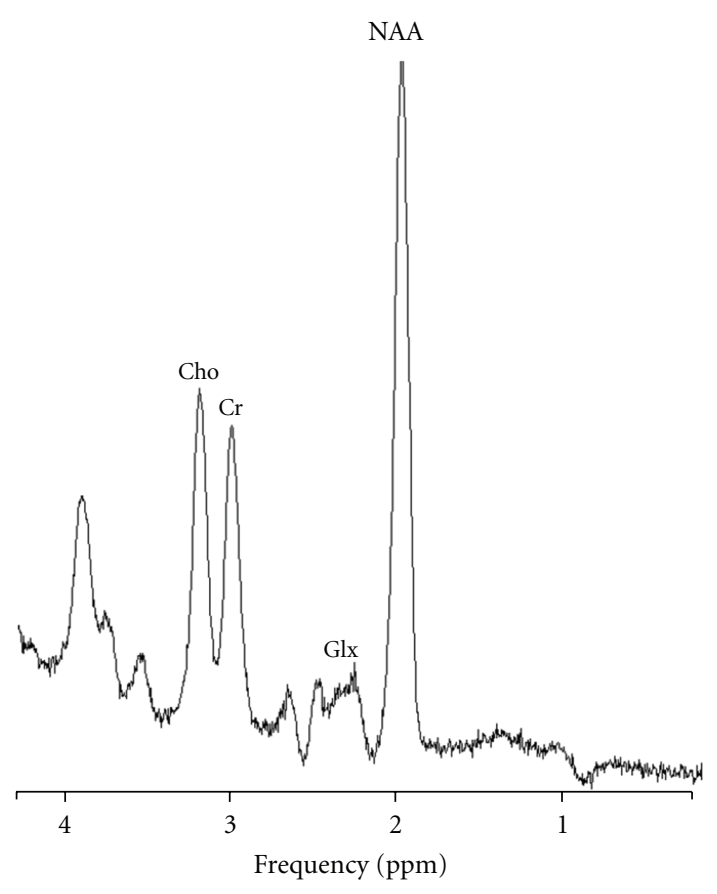

Figure 1: Representative proton $\left({ }^{1} \mathrm{H}\right)$ magnetic resonance spectrum of the anterior cingulate cortex at $3 \mathrm{Tesla}(\mathrm{TR}=2000 \mathrm{~ms}, \mathrm{TE}=135)$. Cho $=$ Choline $\mathrm{Cr}=$ Creatine; $\mathrm{Glx}=$ Glutamine + Glutamate; NAA $=\mathrm{N}$-Acetyl Aspartate; ppm = parts per million.

neurological disorders including drug abuse, schizophrenia, traumatic brain injury, stroke, epilepsy, multiple sclerosis, neoplasm, HIV encephalopathy, and Alzheimer's disease [43].

The Cr peak reflects the sum of the $\mathrm{Cr}$ and Phosphocreatine (PCr) peaks, an important limitation that will be discussed below. The equilibrium maintained between $\mathrm{Cr}$ and $\mathrm{PCr}$ is determined by the cellular demand for the high-energy phosphate stored as creatine phosphate [45]. As its level is considered to be constant, $\mathrm{Cr}$ is often used as an internal standard for comparison [46]. The Cho peak contains four membrane- and myelin-related chemicals [36]: phosphorylethanolamine (PE), phosphorylcholine (PC), glycerophosphorylethanolamine (GPE), and glycerophosphorylcholine (GPC). Cho is a metabolic marker of membrane density and integrity, that is, phospholipid synthesis and degradation [30]. Neuropathology characterized by cell membrane breakdown liberates Cho and increases the free Cho pool, contributing to an increased resonance in neurodegenerative disorders [45]. In traumatic brain injury, Cho levels increase in relation to the severity of neuronal injury resulting from the breakdown of membranes and myelin [47]. Finally, an elevation in the Cho resonance within brain lesions has been accepted as a sign of malignancy $[48,49]$. Myoinositol (mI) is a sugar involved in the regulation of neuronal osmolarity, the metabolism of membrane bound phospholipids, and in the phosphoinositide (PI) secondary messenger pathway [46]. Myo-inositol is considered a marker of glial proliferation, and an increase in $\mathrm{mI}$ resonance may be a proxy for increased inflammation in the brain [50].
Under normal circumstances, lactate (Lac) is present in the brain at concentrations too small to be detected using ${ }^{1} \mathrm{H}-$ MRS. However, if the aerobic oxidation mechanism fails and anaerobic glycolysis is triggered-such as brain ischemia, hypoxia, seizure activity, and metabolic disorders-Lac levels rise significantly [30]. Typically, the Lac peak can be observed as an inverted doublet at an echo time of $135 \mathrm{~ms}$ at $1.3 \mathrm{ppm}$. It has been shown that lactate becomes elevated if large numbers of inflammatory cells are activated [51]. In the past two decades, ${ }^{1} \mathrm{H}$-MRS has progressed from the laboratory into routine use in the treatment of cancers of the brain and prostate [33]. Mood disorders may join the list of disease states in which clinicians can make use of ${ }^{1} \mathrm{H}-\mathrm{MRS}$, if the current pace of neuroimaging research in psychiatry is maintained.

${ }^{31} \mathrm{P}$-MRS is a related neuroimaging method that acquires the resonance spectra of phosphorus rather than hydrogen. Although MRS can be performed on a variety of nuclei such as carbon, nitrogen, fluorine, and sodium, only the nuclei of phosphorus (31P) and hydrogen $(1 \mathrm{H})$ exist in vivo in sufficient concentrations for routine clinical evaluation [52]. Studies employing ${ }^{31} \mathrm{P}$-MRS have indicated possible abnormalities in membrane high-energy phosphate metabolism, phospholipid metabolism, and intracellular $\mathrm{pH}$ in mood disorders [32].

In ${ }^{31} \mathrm{P}$-MRS spectra of the brain, seven chemical peaks are resolved; these are phosphomonoester (PME), inorganic phosphate $(\mathrm{Pi})$, phosphodiester (PDE), phosphocreatine (PCr), and alpha- $(\alpha)$, beta- $(\beta)$, and gamma- $(\gamma)$ nucleoside triphosphate (NTP) $[32,53,54]$. Figure 2 displays an example of the spectra that is acquired.

The $\beta$-NTP peak is measured as a proxy for ATP, the principal energy source in brain. The phosphomonoester (PME) peak contains the signals from numerous metabolites, including those related to membrane phospholipid synthesis such as phosphocholine (PC) or phosphoethanolamine (PE) [55] and sugar phosphates such as glycerophosphate or inositol phosphates [56]. In the PME region, PE is the most abundant and PC is the second most abundant metabolite [57]. The membrane breakdown products glycerophosphocholine and glycerophosphoethanolamine contribute to the PDE peak [58], but most of the signal in the in vivo PDE peak arises from membrane phospholipid itself $[59,60]$, marking PDE as a marker of neuronal integrity. The Pi peak appears between the PME and PDE peaks. Pi appears in many metabolic pathways. Although the Pi peak contains both $\mathrm{PO}_{4}{ }^{-1}$ and $\mathrm{PO}_{4}{ }^{-2}$, they register as one peak due to the rapid exchange between these two molecules. The position of this peak reflects the equilibrium between $\mathrm{PO}_{4}{ }^{-1}$ and $\mathrm{PO}_{4}{ }^{-2}$, a fact that allows investigators to calculate brain $\mathrm{pH}$ from the chemical shift of the Pi peak [61]. Because the phosphate ions exist in the intracellular space, this calculated $\mathrm{pH}$ reflects intracellular $\mathrm{pH}(\mathrm{pHi})$. The PCr peak is the most prominent peak in the ${ }^{31} \mathrm{P}$-MRS spectra in the brain [32]. PCr conveys high-energy phosphates from the mitochondria to the cytosol. When an ATP molecule is consumed, PCr transfers its high-energy phosphate group to ADP (adenosine diphosphate), thus replenishing ATP via the creatine kinase reaction. In this regard, PCr behaves 


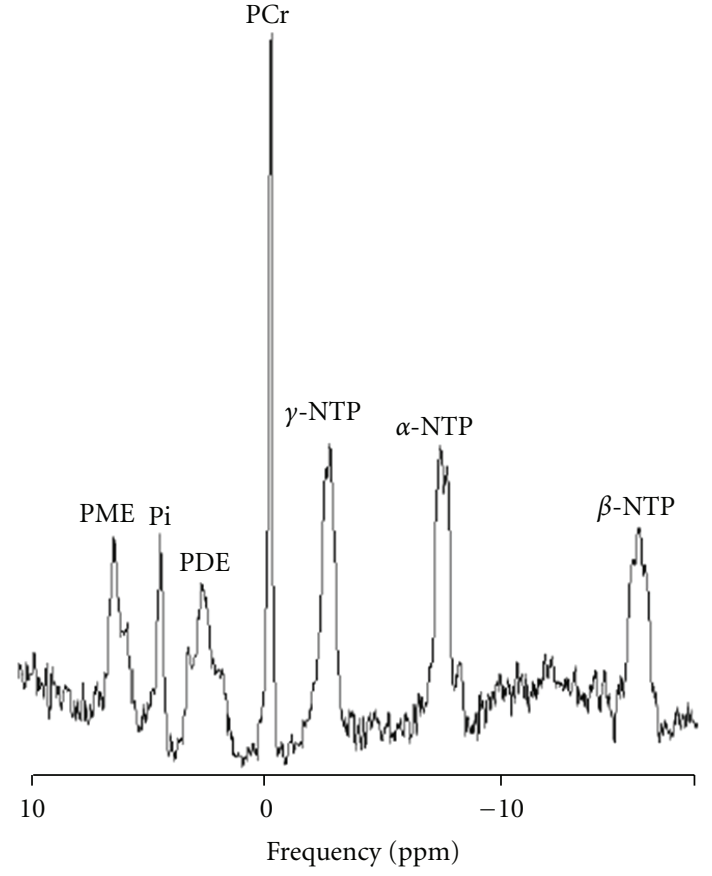

Figure 2: Phosphorus $\left({ }^{31} \mathrm{P}\right)$ magnetic resonance spectrum of the whole brain at 3 Tesla $(\mathrm{TR}=3000 \mathrm{~ms}$, TE $=2.3 \mathrm{~ms})$. PME $=$ phosphomonoester; $\mathrm{Pi}=$ inorganic phosphate; $\mathrm{PDE}=$ phosphodiester; $\mathrm{PCr}=$ phosphocreatine; NTP $=$ Nucleoside Triphosphate; $\mathrm{ppm}=$ parts per million.

as a buffer of ATP [62]. PCr is abundant in tissues with rapidly variable energy demands, that is, brain and muscle tissue. This ATP buffer is absent in tissues where energy demands are constant, such as liver tissue. NTP forms three distinct peaks-alpha- $(\alpha)$, beta- $(\beta)$, and gamma- $(\gamma)$ nucleoside triphosphate- of which the doublet of the $\gamma$ ATP peak is resolved in 31P-MR spectra [32]. ATP is the bioenergetic substrate for many biochemical processes in the brain and is present at a much higher concentration-on the order of $1.8 \mathrm{mM}$ - than any other NTP [63].

For a number of practical reasons, proton spectroscopy is the most widely employed MRS method in psychiatric research. Protons are abundant in organic structures, and their nuclei have high magnetic sensitivity. In $1995,{ }^{1} \mathrm{H}-$ MRS became widely available when the U.S. Food and Drug Administration (FDA) approved the software for an automated and inexpensive MRS sequence protocol, the PROton Brain Examination (PROBE) [31, 64], which can be run without dedicated research personnel on a standard MRI scanner [31]. The majority of ${ }^{1} \mathrm{H}$-MRS studies have been conducted using MRI scanners operating at magnetic field strengths of 1.5 Tesla or less, which is less than optimal for ${ }^{31} \mathrm{P}$-MRS. However, 3 Tesla MRI was approved by the FDA in 2000 [65] and is becoming widely accessible to major medical centers. The increased availability of scanners with 3 or 4 Tesla magnetic fields will improve the sensitivity of MRS studies [66]. At present, to conduct MRS brain scans that target other nuclei of interest to psychiatristssuch as phosphorus or lithium-requires specialized equipment (though not a separate MRI machine!) and research expertise. These obstacles will not be insurmountable, if ${ }^{31} \mathrm{P}$-MRS, in particular, proves to be a valid and reliable measure of one or more translational biomarkers in the affective disorders. To date, unlike physicians in other fields of medicine, psychiatrists do not benefit from working with objective measures of illness and recovery, such as blood pressure or hemoglobin Alc. In the competition to define the first validated biomarker for use in clinical psychiatry, MRS investigators have joined the pursuit along with their colleagues in genetics, neuroscience, and other branches of neuroimaging.

In recent years, multiple studies have reported regional and global hypometabolism in subjects experiencing a major depressive episode, which could be related to the pathophysiology of mood disorders [67]. The literature describes several abnormalities of bioenergetic metabolism in adults, primarily decreased baseline levels of $\beta$-nucleoside triphosphate and total NTP, in the basal ganglia and the frontal lobes of MDD subjects compared with healthy control subjects $[63,68,69]$. Our group recently reported baseline PCr levels could be a predictor of depression treatment outcomes [67]. Thus, ${ }^{31} \mathrm{P}$-MRS provides investigators with a robust methodology [70], with which it is now possible to test specific hypotheses regarding the neurobiology of mood disorders in adults. MDD is a common and disabling illness that often begin in adolescence [23, 71-73]. Given the well-established safety of MRI, further study of pediatric mood disorders utilizing ${ }^{31} \mathrm{P}-$ MRS represents a rational endeavor in an attempt to expand the evidence base in medicine.

\section{Materials and Methods}

3.1. Search Strategy. A literature search using the U.S. National Library of Medicine's PubMed database was conducted to identify peer-reviewed neuroimaging MRS research studies of children and adolescents with MDD that were published between January 1966 to March 2010. The following terms were included in the search: "magnetic resonance spectroscopy," "depressive disorder," "mood disorder or affective disorder," and "child or adolescent or pediatric or early-onset." We performed a backward search of bibliographic references from the identified articles to ensure the inclusion of relevant articles. A forward citation search for identified studies was also performed. Studies that recruited a mixture of adults and children were not included. All relevant articles published in English were included, and due to the small number of studies no methodological exclusion criteria were applied.

\section{Results and Discussion}

The literature search yielded 18 articles reporting original MRS data in pediatric MDD: 13 studies in MDD and 5 in children and adolescents with mood disorders not meeting full diagnostic criteria for MDD. Table 1 presents the published MRS studies in pediatric MDD, all of which employed ${ }^{1} \mathrm{H}$-MRS. 
TABLE 1: Magnetic resonance spectroscopy studies of pediatric major depressive disorder.

\begin{tabular}{|c|c|c|c|c|}
\hline Study & Sample & $\begin{array}{c}\text { Field } \\
\text { strength }\end{array}$ & Voxel size \& location & Findings \\
\hline $\begin{array}{l}\text { Caetano, } \\
\text { et al. } 2005 \\
{[83]}\end{array}$ & $\begin{array}{c}\text {-14 MDD (mean age } \\
\text { 13.6)-22 Healthy } \\
\text { Controls (mean age } \\
13.3 \text { ) }\end{array}$ & 1.5 Tesla & $\begin{array}{l}8 \mathrm{cc} \text { in the Left Dorsolateral } \\
\text { Prefrontal Cortex }\end{array}$ & $\begin{array}{l}\Downarrow \text { glycerophosphocholine }+ \\
\text { phosphocholine (GPC + PC; or } \\
\text { choline-containing compounds) in } \\
\text { MDD patients. } \Uparrow \text { Inositol and } \\
\text { myo-Inositol levels in MDD patientsIn } \\
\text { MDD patients Glutamate level is } \\
\text { inversely correlated with Duration of } \\
\text { Illness as well as Number of Episodes }\end{array}$ \\
\hline $\begin{array}{l}\text { Farchione } \\
\text { et al. } 2002 \\
{[76]}\end{array}$ & $\begin{array}{l}-11 \text { treatment-naive } \\
\text { MDD patients (mean } \\
\text { age } 14.3)-11 \text { healthy } \\
\text { controls (mean age } \\
14.3 \text { ) }\end{array}$ & 1.5 Tesla & $\begin{array}{l}0.8 \mathrm{cc} \text { in the Left and Right } \\
\text { Dorsolateral Prefrontal } \\
\text { Cortex }\end{array}$ & $\begin{array}{l}\Uparrow \text { Cho was observed in left (but not } \\
\text { right) DLPFC in MDD patients versus } \\
\text { healthy controls ( } 32.5 \% \text { higher)No } \\
\text { difference in NAA or Cr were observed } \\
\text { between case-control pairs }\end{array}$ \\
\hline $\begin{array}{l}\text { Gabbay } \\
\text { et al. } 2009 \\
{[89]}\end{array}$ & $\begin{array}{l}-7 \text { MDD patients } \\
\text { (mean age } 16.2 \text { ) with } \\
\text { Melancholic } \\
\text { Features-7 patients } \\
\text { (mean age 16.9) with } \\
\text { non-melancholic, } \\
\text { reactive MDD-6 } \\
\text { healthy comparison } \\
\text { patients (mean age } \\
16.2 \text { ) }\end{array}$ & 3 Tesla & $\begin{array}{l}10 \mathrm{~cm} \text { anterior-posterior } \\
(\mathrm{AP}) \times 7 \mathrm{~cm} \text { left-right }(\mathrm{LR}) \\
\times 6 \mathrm{~cm} \text { inferior-superior } \\
(\mathrm{IS})=420 \mathrm{~cm} 3 \text { in the Left } \\
\text { Putamen and Right } \\
\text { Caudate }\end{array}$ & $\begin{array}{l}\text { No significant correlations were found } \\
\text { in the healthy control group or in the } \\
\text { MDD group as a wholeIn Melancholic } \\
\text { patients, plasma Kynurenine } \\
\text { concentrations were positively } \\
\text { correlated with Right Caudate total } \\
\text { CholineIn Melancholic patients, plasma } \\
\text { 3-hydroxyanthranilic acid (3-HAA), a } \\
\text { neurotoxic intermediate of the } \\
\text { Kynurenine Pathway) was positively } \\
\text { correlated with Left Putamen total } \\
\text { Choline }\end{array}$ \\
\hline
\end{tabular}

-14 adolescents(mean age 16.2 years) who had symptoms of MDD for 8 weeks and a score $\geq 40$

Gabbay

et al. 2007

[86]

(mean=63.6) on the

Children's Depression Rating

Scale-Revised-10

healthy comparison patients

Kusumakar, et al. 2001

[75]

MacMaster et al. 2008

[87]

MacMaster

and

Kusumakar, 2006 [84]

Mirza et al. 2004 [80]

$$
\begin{gathered}
\text {-11 MDD (mean age } \\
\text { 16.7)-11 Healthy } \\
\text { Controls (mean age } \\
16.6)
\end{gathered}
$$

$$
\begin{gathered}
11 \text { MDD, } 11 \text { Healthy } \\
\text { Controls }
\end{gathered}
$$

1.5Tesla

-12 MDD-11 Healthy Controls (10-18 y/o; 7 females and 5 males per group)

$$
-13
$$

psychotropic-naïve with MDD (mean age 15.5)-13 healthy controls (mean age 15.4)

1.5 Tesla

1.5 Tesla
16 (anterior-posterior) $\times$ 16 (left-right) voxels, each 3 Tesla anominal $0.75 \mathrm{~cm}^{3}$ in the left and right caudate, putamen and thalamus

Multivoxel: 6x6 placed in anterior medial temporal region (amygdala)

$0.8 \mathrm{~mL}$ voxel in the left and right Medial Temporal Cortex

$4 \mathrm{cc}$ in the right prefrontal cortex

$2 \times 1.5 \times 1 \mathrm{~cm}=3 \mathrm{cc}$ volume centered on the anterior cingulate cortex
Adolescents with MDD had significantly $\Uparrow$ concentrations of choline $(2.11 \mathrm{mM}$ versus $1.56 \mathrm{mM})$ and creatine $(6.65 \mathrm{mM}$ versus $5.26 \mathrm{mM}$ ) in the left caudate. No other neurochemical differences were observed between groups

$\Downarrow$ Left amygdala Cho-Cr ratios in MDD patients compared with controlsLeft amygdala NAA-Cr and right amygdala Cho-Cr and NAA-Cr did not differ significantly between patients with depression and control patients

$\Downarrow \mathrm{N}$-acetyl-aspartate in theleft medial temporal cortex $(27 \%)$ in MDD patients versus healthy controls

$\Uparrow$ Right prefrontal cortex Choline/Creatine ratio in MDD compared with healthy controls $(p=.007)$

Anterior cingulate glutamatergic (Glx) concentrations were significantly $\Downarrow$ (19\% decrease) in MDD patients versus controls $(9.27+/-0.43$ versus $11.47+/$ 0.26 , respectively, $p=.000$ ) 
Table 1: Continued.

\begin{tabular}{|c|c|c|c|c|}
\hline Study & Sample & $\begin{array}{c}\text { Field } \\
\text { strength }\end{array}$ & Voxel size \& location & Findings \\
\hline $\begin{array}{l}\text { Mirza et al. } \\
2006[85]\end{array}$ & $\begin{array}{c}18 \text { pediatricpatients } \\
\text { with major depressive } \\
\text { disorder } 9 \text { to } 17 \text { years } \\
\text { of age, } 18 \\
\text { case-matched healthy } \\
\text { controls, and } 27 \\
\text { patients } \\
\text { withobsessive- } \\
\text { compulsive disorder } 7 \\
\text { to } 16 \text { years old }\end{array}$ & 1.5 Tesla & $\begin{array}{l}0.8 \mathrm{~mL} \text { voxel in the medial } \\
\text { thalamus }\end{array}$ & $\begin{array}{l}\Uparrow \text { left and right medial } \\
\text { thalamiccreatine-phosphocreatine } \\
\text { concentrations in patients with OCD } \\
\text { compared with both healthy controls } \\
\text { and patients with } \\
\text { MDDCreatine-phosphocreatine } \\
\text { concentrations did not differ } \\
\text { significantly betweenpatients with } \\
\text { MDD and healthy controls }\end{array}$ \\
\hline $\begin{array}{l}\text { Rosenberg } \\
\text { et al. } 2005 \\
{[82]}\end{array}$ & $\begin{array}{l}\text { 14 MDD patients } \\
\text { (man age 15.6)14 } \\
\text { healthy controls } \\
\text { (mean age } 15.5 \text { ) }\end{array}$ & 1.5 Tesla & $\begin{array}{l}2 \times 1.5 \times 1 \mathrm{~cm}=3 \mathrm{cc} \\
\text { centered on the Anterior } \\
\text { Cingulate Cortex }\end{array}$ & $\begin{array}{l}\Downarrow \text { anterior cingulate glutamate in MDD } \\
\text { patients compared with controls } \\
(p=.0002 ; 23 \% \text { decrease) No difference } \\
\text { in anterior cingulate glutamine }\end{array}$ \\
\hline $\begin{array}{l}\text { Rosenberg, } \\
\text { et al. } 2004 \\
{[81]}\end{array}$ & $\begin{array}{c}-14 \\
\text { psychotropic-naïve } \\
\text { patients with } \\
\text { MDDwithout OCD } \\
\text { (mean age 15.6)-20 } \\
\text { non-depressed, } \\
\text { patients with OCD } \\
\text { (mean age 11.4)-14 } \\
\text { healthy controls } \\
\text { (mean age } 15.5 \text { ) }\end{array}$ & 1.5 Tesla & $\begin{array}{l}2 \times 1.5 \times 1 \mathrm{~cm}=3 \mathrm{~mL} \text { in } \\
\text { the Anterior Cingulate } \\
\text { Cortex }\end{array}$ & $\begin{array}{l}\Downarrow \text { Anterior cingulate glutamatergic } \\
(\text { Glx) concentrations were significantly } \\
\text { in OCD patients }(15.1 \% \text { decrease }) \text { and } \\
\text { MDD patients ( } 18.7 \% \text { decrease }) \\
\text { compared with controls }(p=.002)\end{array}$ \\
\hline $\begin{array}{l}\text { Smith et al. } \\
2003 \text { [77] }\end{array}$ & $\begin{array}{l}\text {-18 drug naive } \\
\text { outpatients with } \\
\text { MDD without OCD } \\
\text { (mean age } 14.4 \text { )- } 27 \\
\text { drug-naive patients } \\
\text { with OCD (mean age } \\
\text { 10.3)-18 healthy } \\
\text { controls (mean age } \\
14.4 \text { ) }\end{array}$ & 1.5 Tesla & $\begin{array}{l}0.8 \mathrm{~mL} \text { voxel in the left and } \\
\text { right medial and lateral } \\
\text { thalamus }\end{array}$ & $\begin{array}{l}\Uparrow \text { left and right medial thalamic } \\
\text { Choline concentrations in OCD } \\
\text { patients compared with both healthy } \\
\text { controls and patients with MDD }\end{array}$ \\
\hline $\begin{array}{l}\text { Steingard, } \\
\text { et al. } 2000 \\
{[74]}\end{array}$ & $\begin{array}{l}-17 \text { MDD patients } \\
\text { (mean age } 15.8)-28 \\
\text { healthy controls } \\
\text { (mean age } 14.5)\end{array}$ & 1.5 Tesla & $\begin{array}{l}15 \mathrm{~mm} \times 15 \mathrm{~mm} \times 15 \mathrm{~mm} \\
\left(3.38 \mathrm{~cm}^{3}\right) \text { voxel in the Left } \\
\text { Orbitofrontal Cortex }\end{array}$ & $\begin{array}{l}\Uparrow \text { Choline/Creatine ratio in MDD } \\
\text { compared with controls } \Uparrow \text { Choline/NAA } \\
\text { ratio in MDD compared with controls }\end{array}$ \\
\hline
\end{tabular}

Following up on their report of structural abnormalities in the brains of children hospitalized for depression, Steingard and colleagues reported in 2000 finding increased choline/creatine ratios and increased choline/NAA ratios in the left orbitofrontal cortex of adolescents with MDD compared with controls [74]. This suggested that brain cytosolic choline may be increased in depressed adolescents, independent of corresponding structural changes, results that were consistent with studies in adults with MDD. This report was followed in 2001 by Kusumaker's finding of decreased choline/creatine ratios in the left amygdala [75], which again implicated choline in the pathophysiology of pediatric MDD. In 2002, Farchione et al. studied the left and right dorsolateral prefrontal cortex in medication-naïve adolescents with MDD and healthy controls. A significant increase in choline was observed in left-but not right-dorsolateral prefrontal cortex in MDD patients versus controls (32.5\% higher) [76].
In a three-armed ${ }^{1} \mathrm{H}-\mathrm{MRS}$ study, Smith et al. compared medication-naïve MDD patients with Obsessive-Compulsive Disorder (OCD) patients and healthy controls. Following up on a prior finding of choline alterations in OCD, the investigators studied the thalamus and found increased choline concentrations bilaterally in the medial thalamus in pediatric OCD patients compared with both MDD patients and controls; they found no difference in medial thalamic choline between MDD patients and control subjects [77]. The potential of MRS in pediatric mood disorders was confirmed by these initial studies in pediatric MDD, which joined studies in adult MDD and preclinical animal research in implicating choline alterations in the disorder $[78,79]$.

Two pediatric MDD ${ }^{1} \mathrm{H}-\mathrm{MRS}$ studies were published in 2004. Mirza et al. compared medication-naïve patients with healthy controls and found a 19\% decrease in glutamatergic (Glx) concentrations in the anterior cingulate 
cortex in the MDD patients [80]. A second study of the anterior cingulate cortex found lower Glx concentrations in both MDD patients (18.7\% decrease) and OCD patients (15.1\% decrease) compared with healthy controls [81]. In the following year, two additional studies were published. Rosenberg et al. separated the Glutamate and Glutamine peaks and found 23\% lower Glutamate concentrations in the anterior cingulate cortex of MDD patients compared with controls $(P=.0002)$ [82]. Caetano and colleagues conducted a case-control study of the left dorsolateral prefrontal cortex and reported decreased choline-containing compounds and increased myoinositol concentrations in patients with MDD [83]. MacMaster andKusumakar reported results of their ${ }^{1} \mathrm{H}$ MRS study of the right prefrontal cortex in 2006, finding that choline/creatine ratio was elevated in MDD patients compared with healthy controls [84]. That same year, Mirza et al. published a study comparing patients with OCD with MDD and control subjects. The OCD patients demonstrated increased choline/Phosphocreatine concentrations in the left and right medial thalamus [85].

In recent years, investigators have expanded the range of structures and metabolites under study. Gabbay et al. reported in 2007 that adolescents with MDD had increased concentrations of both choline and creatine in the left (but not the right) caudate nucleus [86]. In 2008, MacMaster et al. were the first to report alterations in NAA in pediatric MDD, finding a $27 \%$ decrease in NAA in the left medial temporal cortex in affected subjects versus healthy controls [87]. Finally, Gabbay and colleagues obtained proton spectra with a 3 Tesla scanner and produced findings that begin to parse the subtypes of pediatric mood disorders on a neurobiological level by focusing on immune system dysregulation in pediatric MDD [88]. The investigators reported that in patients with melancholic features, plasma Kynurenine levels were positively correlated with choline concentrations in the right caudate nucleus and plasma 3-hydroxyanthranilic acid, a neurotoxic intermediate of the Kynurenine Pathway, was positively correlated with left putamen total choline [89].

Taken together, the consistency of findings in pediatric MDD validates the utility of MRS as a translational tool for studying pediatric MDD and adds to the converging lines of evidence suggesting that pediatric MDD is continuous with adult MDD [90].

\section{Conclusions}

A decade ago, Hendren et al. reviewed the neuroimaging literature in child and adolescent psychiatry and called for researchers to "identify clear structure/function hypotheses when studying childhood mental disorders that use but go beyond DSM diagnoses [91]." Echoing this sentiment, the research agenda for DSM-V emphasizes the need to translate findings from clinical neuroscience research into a new classification system based upon pathophysiology and etiological processes $[92,93]$. As it continues to mature as a method, MRS is positioned to make a contribution to this evolution in psychiatry. In vivo MRS is the only noninvasive imaging technique capable of directly assessing the living biochemistry in localized brain regions [94]. Studies of depressed children and adolescents have a number of advantages compared with studies of adults: the effects of statistical covariates such as repeated episodes, duration of illness, multiple medications, and normal aging are avoided. Thus, MRS may be a translational research tool capable of partially obviating the developmental and environmental confounders that have made research in child psychiatry a difficult challenge.

Researchers working with pediatric MDD populations have reported MRS findings that implicate Glx, NAA, and choline (including its correlation with immune system metabolites) in the neurobiology of MDD. Altered levels of choline would be consistent with altered neural plasticity as well as animal models of depression and antidepressant response [95]. No study identified in our literature search used repeated measures MRS scans to ascertain if there are changes in neurometabolite concentrations when a child with MDD responds to treatment, that is, whether the baseline differences in Glx, NAA, and choline are differences of "state" or "trait". Pavuluri and Sweeney have argued for the importance of obtaining functional neuroimaging measures before and after pharmacologic intervention [9], and the feasibility of this approach is demonstrated in several published studies of depressed adults [67, 96, 97]. Results from such studies will shed light on the mechanisms by which antidepressants work and may provide new treatment targets for drug development [13, 98]. In addition to pointing toward the mechanisms of illness recovery (i.e., the "mediators" [99]), Pavuluri also emphasizes the potential for neuroimaging studies to identify predictors of treatment outcome [9] (i.e., the "moderators" [99]). Identification of the mediators and moderators of pediatric MDD treatment would serve the NIMH's stated goal of moving toward personalized care.

Research in mood-disordered adults [67, 68, 100-103], combined with preclinical animal studies of depression [104-107], has given rise to the bioenergetic hypothesis, which proposes that altered energy metabolism is a reversible correlate of pathogenesis of mood disorders [108-110]. Converging lines of evidence from electron microscopy, gene expression, genotyping, and sequencing studies implicate mitochondrial dysfunction in MDD [111]. Neuroimaging studies using MRS have convincingly demonstrated that MDD is associated with mitochondrial dysfunction [73, 77$79,112]$. More specifically, a growing body of research shows that MDD subjects have decreased beta nucleoside triphosphate (b-NTP) and increased levels of phosphocreatine (PCr) compared with healthy controls $[73,78,79]$. Furthermore, successful treatment of MDD with antidepressants is associated with normalization in both NTP and PCr levels $[79,112]$.

Contemporary understanding of the neurobiology of depression is focused on imbalances in neural circuits [12], cellular plasticity and resilience $[113,114]$, and impaired neurotrophic signaling cascades [115] (for an excellent review, see Carlson et al. [116]; for the conceptual framework, see and Manji et al. [117] and Duman et al. [118]). As a research tool, MRS is unique in its ability to perform in vivo quantification of the neurometabolite indicators of neuronal 
integrity, mitochondrial functioning, cellular membrane turnover, and signaling cascades [66]. Finally, MRS is the only known method for in vivo measurement of gammaaminobutyric acid (GABA) concentration $[41,119]$, which plays an increasingly central role in our conceptualization of mood disorders [120-123]. As the field matures, it has the potential to play a major role in delineating the neurobiology of MDD.

5.1. What Are the Limitations of MRS? While MRS studies have the potential to provide unique insights into the neurobiology of pediatric MDD, technical limitations must be acknowledged. As with all neuroimaging modalities, the number of patients enrolled in a given study tends to be small. Comparison between studies (and therefore replication of key findings) is difficult, due to differences in spectra acquisition protocols and the fact that calculation of the area under a given spectral peak is open to considerable interpretation [36]; the optimal method for quantification of neurochemicals has yet to be determined. In addition, the generalizability of MRS studies is limited by potential confounds such as medication effects, duration of illness, comorbidity, and gender [124]. At present, MRS has less temporal and spatial resolution compared with MRI and functional MRI (fMRI) [125]. The volume of the braincalled the "voxel" - that is sampled in a typical ${ }^{1} \mathrm{H}$-MRS study is $\leq 8 \mathrm{~mL}$ (larger for ${ }^{31} \mathrm{P}$-MRS scans). This is problematic in the light of current models of depressive disorders, which suggest the presence of altered interactions between hierarchically distributed neural networks which are widely distributed throughout the brain [126]. Another issue is the relatively small number of metabolites that can be assayed using MRS. "Key players" such as dopamine, serotonin, and norepinephrine are not visible to an MRS scanner [38]. Finally, scanning times are relatively long (up to 90 minutes), which increases the burden on research participants and limits patient acceptance.

5.2. What Would a Child Psychiatrist Want to Know about MRS? With the current emphasis on translational research in medicine, the question of science's relevance to practicing clinicians is ever-present. Busy child and adolescent psychiatrists are faced on a daily basis with questions that further study utilizing MRS has the potential to answer.

(i) How can we distinguish bipolar disorder (BD) from $M D D$ ? Chang et al. posed the question of whether neuroimaging will be used to diagnose $\mathrm{BD}$ in a 2006 publication, concluding that use of MRS variables such as mI or NAA for diagnosis is problematic at present, due to the variable of mood state and the lack of standardized methods for performing and interpreting the scans [112]. If children with both $\mathrm{BD}$ and MDD were followed and scanned longitudinally, MRS would be able to test the hypothesis that the major depressive episodes experienced by both groups of patients have the same neurochemical basis. (ii) What is a problem of state versus a problem of trait? The ability of MRS to measure neurochemical changes that parallel changes in patients' clinical presentation is now well established in children and adults. In addition, further study of children and adolescents would help determine whether differences in depressed patients are the result of altered development across the life span, or if they can be documented early in development, serving as a risk factor for which prevention strategies might be employed [74].

(iii) Can MRS help clinicians assess the effects of medication? Our literature search did not find any publications utilizing MRS to measure changes in the brain in pediatric MDD treatment studies.

(iv) What is the specificity of MRS in mood disorders? The results thus far suggest that MRS can find neurochemical differences between mood disorders and OCD [77], Intermittent Explosive Disorder [127], and Attention-deficit Hyperactivity Disorder (ADHD) [128].

An illustrative example of the potential for specificity offered by MRS is the case of Glx and ADHD. Investigators have found elevated Glx in brain regions of interest in ADHD patients compared to healthy controls.Duman et al. [118] found increased Glx in the right prefrontal cortex and striatum of ADHD subjects, Courvoisie [119] documented increased Glx in the left and right frontal lobes, and Klempan et al. [120] found elevated Glx concentrations in the striatum treatment-naïve ADHD patients. In addition, Carey et al. have shown that changes in glutaminergic tone occur with ADHD treatment $[129,130]$. In contrast to the findings in ADHD, Rosenberg [81] and Mirza [80] have shown that Glx is reduced in MDD, and Moore et al. [128] found that pediatric Bipolar Disorder with and without ADHD is differentiated by Glx concentrations in the anterior cingulate cortex.

\subsection{What Should Future MRS Studies in Pediatric Mood} Disorders Look Like? Some twenty years ago, Bottomley enumerated the "trouble with spectroscopy papers" [131], lamenting the fact that a research tool with such precision had given rise to a medical literature whose findings are not easily reconciled. Noting the lack of standards for the conduct and reporting of clinical MRS research, Bottomley recommended that authors provide objective, rigorously quantified results and that spectra acquisition protocols be described in sufficient details that experiments could be reproduced [131]. More recently,Kreis [132] and Taylor [133] have argued cogently for the field of clinical MR spectroscopy to establish a set of scientific and quality assurance guidelines. This process is underway in oncological neuroradiology [134-136], but widely accepted standards have yet to be established in psychiatry. As shown in Table 1 , the MRS literature in pediatric MDD presents the reader with a diversity of techniques, anatomical reference points, and neurochemical findings. Future studies would benefit 
from standardized protocol design and data reporting: as Leibenluft [13] has observed, psychiatric neuroimaging articles can be "confusing, tedious to read and...boring"even for researchers in the field. For MRS studies of mood disorders to become a truly translational body of research, investigators will need to communicate their findings to the wider psychiatric community in a clear and intuitive manner; establishment of an expert consensus regarding best practices in MRS research and reporting would be a significant early step toward that goal.

Two important gaps in the medical literature were identified by the PubMed search on which this paper is based. The first is that there were no peer-reviewed publications reporting ${ }^{31} \mathrm{P}$-MRS data in pediatric MDD. ${ }^{31} \mathrm{P}$-MRS has the unique ability to measure high-energy phosphorus metabolites in vivo $[63,68,69,137]$, which is important because dysfunction in neuronal energy metabolism may be one mechanism of depression [109]. Second, no pediatric MDD clinical trials were identified in which MRS brain scans were used as a repeated measure, that is, performed pre- and posttreatment in order to learn which, if any, MRS metabolites were altered by the study treatment intervention. In contrast to their absence in the pediatric MDD literature, repeated measures MRS scans have often been incorporated into treatment studies of pediatric Bipolar Disorder [138$141]$ and related conditions $[142,143]$. Incorporating ${ }^{31} \mathrm{P}-$ MRS methodology and repeated measures study design into pediatric MDD clinical trials could provide fundamental insights into the neurobiology of MDD.

In conclusion, MRS is an emerging translational research tool for the study of pediatric MDD. The bulk of published MRS depression studies have been done in adult populations, but mood disorders often begin in adolescence and there is much to be learned by studying young people who are early in the course of the disorder. The non-invasive nature and relative safety of MRS make this possible. Well-designed future MRS studies in pediatric MDD will shed light on the neurobiology of depression, help to define the physiologic mechanisms illness and recovery, and identify treatment targets for the development of new interventions.

\section{Acknowledgments}

This paper was supported by a NARSAD Young Investigator Award to Dr. Kondo, National Institute of Mental Health Grant no. 5R01MH058681 to Dr. Renshaw, the Utah Science Technology and Research Initiative (USTAR) at the University of Utah, and a Funding Incentive Seed Grant from the University of Utah Research Foundation.

\section{References}

[1] W. K. Goodman, "Research on Biomarkers for Mental Disorders," National Institute of Mental Health, Bethesda, Md, USA, 2009 http://www.nimh.nih.gov/research-funding /grants/concept-clearances/2009/research-on-biomarkers -for-mental-disorders.shtml?WT.mc_id=rss.
[2] A. J. Atkinson Jr., W. A. Colburn, V. G. DeGruttola et al., "Biomarkers and surrogate endpoints: preferred definitions and conceptual framework," Clinical Pharmacology and Therapeutics, vol. 69, no. 3, pp. 89-95, 2001.

[3] D. A. Regier, W. E. Narrow, E. A. Kuhl, and D. J. Kupfer, "The conceptual development of DSM-V," American Journal of Psychiatry, vol. 166, no. 6, pp. 645-650, 2009.

[4] D. S. Charney, D. H. Barlow, K. Botterton, J. D. Cohen, D. Goldman, and R. E. Gur, "Neuroscience research agenda to guide development of a pathophysiologically based classification system," in A Research Agenda for DSM-V, D. J. Kupfer, M. B. First, and D. A. Regier, Eds., American Psychiatric Publishing, Arlington, Va, USA, 2002.

[5] M. L. Phillips, "The emerging role of neuroimaging in psychiatry: characterizing treatment-relevant endophenotypes," American Journal of Psychiatry, vol. 164, no. 5, pp. 697-699, 2007.

[6] I. Singh and N. Rose, "Biomarkers in psychiatry," Nature, vol. 460, no. 7252, pp. 202-207, 2009.

[7] S. E. Hyman, "Can neuroscience be integrated into the DSMV?" Nature Reviews Neuroscience, vol. 8, no. 9, pp. 725-732, 2007.

[8] C. F. Reynolds III, D. A. Lewis, T. Detre, A. F. Schatzberg, and D. J. Kupfer, "The future of psychiatry as clinical neuroscience," Academic Medicine, vol. 84, no. 4, pp. 446450, 2009.

[9] M. N. Pavuluri and J. A. Sweeney, "Integrating functional brain neuroimaging and developmental cognitive neuroscience in child psychiatry research," Journal of the American Academy of Child and Adolescent Psychiatry, vol. 47, no. 11, pp. 1273-1288, 2008.

[10] J. A. Serene, M. Ashtari, P. R. Szeszko, and S. Kumra, "Neuroimaging studies of children with serious emotional disturbances: a selective review," Canadian Journal of Psychiatry, vol. 52, no. 3, pp. 135-145, 2007.

[11] A. J. Gerber and B. S. Peterson, "Applied brain imaging," Journal of the American Academy of Child and Adolescent Psychiatry, vol. 47, no. 3, p. 239, 2008.

[12] W. C. Drevets, J. L. Price, and M. L. Furey, "Brain structural and functional abnormalities in mood disorders: implications for neurocircuitry models of depression," Brain Structure and Function, vol. 213, no. 1-2, pp. 93-118, 2008.

[13] E. Leibenluft, "Skating to where the puck will be: the importance of neuroimaging literacy in child psychiatry," Journal of the American Academy of Child and Adolescent Psychiatry, vol. 47, no. 11, pp. 1213-1216, 2008.

[14] J. N. W. Friedman, R. A. Hurley, and K. H. Taber, "Bipolar disorder: imaging state versus trait," Journal of Neuropsychiatry and Clinical Neurosciences, vol. 18, no. 3, pp. 296-301, 2006.

[15] M. A. H. Rot, S. J. Mathew, and D. S. Charney, "Neurobiological mechanisms in major depressive disorder," Canadian Medical Association Journal, vol. 180, no. 3, pp. 305-313, 2009.

[16] World Health Organization, The Global Burden of Disease: 2004 Update, WHO Press, Geneva, Switzerland, 1st edition, 2008.

[17] R. C. Kessler, S. Avenevoli, J. Green et al., "National comorbidity survey replication adolescent supplement (NCS-A): III. concordance of DSM-IV/CIDI diagnoses with clinical reassessments," Journal of the American Academy of Child and Adolescent Psychiatry, vol. 48, no. 4, pp. 386-399, 2009. 
[18] T. Paus, M. Keshavan, and J. N. Giedd, "Why do many psychiatric disorders emerge during adolescence?" Nature Reviews Neuroscience, vol. 9, no. 12, pp. 947-957, 2008.

[19] B. Birmaher, D. Brent, W. Bernet, O. Bukstein, H. Walter, and R. S. Benson, "Practice parameter for the assessment and treatment of children and adolescents with depressive disorders," Journal of the American Academy of Child and Adolescent Psychiatry, vol. 46, no. 11, pp. 1503-1526, 2007.

[20] P. M. Lewinsohn, H. Hops, R. E. Roberts, J. R. Seeley, and J. A. Andrews, "Adolescent psychopathology: I. Prevalence and incidence of depression and other DSM-III-R disorders in high school students," Journal of Abnormal Psychology, vol. 102, no. 1, pp. 133-144, 1993.

[21] D. M. Fergusson, L. J. Horwood, E. M. Ridder, and A. L. Beautrais, "Subthreshold depression in adolescence and mental health outcomes in adulthood," Archives of General Psychiatry, vol. 62, no. 1, pp. 66-72, 2005.

[22] F. L. Lynch and G. N. Clarke, "Estimating the economic burden of depression in children and adolescents," American Journal of Preventive Medicine, vol. 31, no. 6, supplement 1, pp. 143-151, 2006.

[23] R. C. Kessler, S. Avenevoli, and K. Ries Merikangas, "Mood disorders in children and adolescents: an NIMH perspective," Biological Psychiatry, vol. 49, no. 12, pp. 962-969, 2001.

[24] E. Fombonne, G. Wostear, V. Cooper, R. Harrington, and M. Rutter, "The Maudsley long-term follow-up of child and adolescent depression: 2. Suicidality, criminality and social dysfunction in adulthood," British Journal of Psychiatry, vol. 179, pp. 218-223, 2001.

[25] E. Fombonne, G. Wostear, V. Cooper, R. Harrington, and M. Rutter, "The Maudsley long-term follow-up of child and adolescent depression: I. Psychiatric outcomes in adulthood," British Journal of Psychiatry, vol. 179, pp. 210-217, 2001.

[26] B. Vitiello, P. Rohde, S. Silva et al., "Functioning and quality of life in the Treatment for Adolescents with Depression Study (TADS)," Journal of the American Academy of Child and Adolescent Psychiatry, vol. 45, no. 12, pp. 1419-1426, 2006.

[27] M. M. Weissman, S. Wolk, R. B. Goldstein et al., "Depressed adolescents grown up," Journal of the American Medical Association, vol. 281, no. 18, pp. 1707-1713, 1999.

[28] E. M. Purcell, H. C. Torrey, and R. V. Pound, "Resonance absorption by nuclear magnetic moments in a solid," Physical Review, vol. 69, no. 1-2, pp. 37-38, 1946.

[29] F. Bloch, W. W. Hansen, and M. Packard, "Nuclear induction," Physical Review, vol. 69, no. 3-4, p. 127, 1946.

[30] D. P. Soares and M. Law, "Magnetic resonance spectroscopy of the brain: review of metabolites and clinical applications," Clinical Radiology, vol. 64, no. 1, pp. 12-21, 2009.

[31] E. R. Danielsen and B. Ross, Eds., Magnetic Resonance Spectroscopy Diagnosis of Neurological Diseases, Marcel Dekker, New York, NY, USA, 1st edition, 1999.

[32] T. Kato, T. Inubushi, and N. Kato, "Magnetic resonance spectroscopy in affective disorders," Journal of Neuropsychiatry and Clinical Neurosciences, vol. 10, no. 2, pp. 133-147, 1998.

[33] R. W. Prost, "Magnetic resonance spectroscopy," Medical Physics, vol. 35, no. 10, pp. 4530-4544, 2008.

[34] N. Agarwal, J. D. Port, M. Bazzocchi, and P. F. Renshaw, "Update on the use of MR for assessment and diagnosis of psychiatric diseases," Radiology, vol. 255, no. 1, pp. 23-41, 2010.

[35] R. A. de Graaf, In Vivo NMR Spectroscopy: Principles and Techniques, John Wiley \& Sons, West Sussex, UK, 2nd edition, 2010.
[36] S. R. Dager, N. M. Corrigan, T. L. Richards, and S. Posse, "Research applications of magnetic resonance spectroscopy to investigate psychiatric disorders," Topics in Magnetic Resonance Imaging, vol. 19, no. 2, pp. 81-96, 2008.

[37] R. Kreis, T. Ernst, and B. D. Ross, "Development of the human brain: in vivo quantification of metabolite and water content with proton magnetic resonance spectroscopy," Magnetic Resonance in Medicine, vol. 30, no. 4, pp. 424-437, 1993.

[38] E. J. Novotny Jr., R. K. Fulbright, P. L. Pearl, K. M. Gibson, and D. L. Rothman, "Magnetic resonance spectroscopy of neurotransmitters in human brain," Annals of Neurology, vol. 54, no. 6, supplement, pp. S25-S31, 2003.

[39] D. E. Bergles, J. S. Diamond, and C. E. Jahr, "Clearance of glutamate inside the synapse and beyond," Current Opinion in Neurobiology, vol. 9, no. 3, pp. 293-298, 1999.

[40] C. M. Moore, J. Biederman, J. Wozniak et al., "Mania, glutamate/glutamine and risperidone in pediatric bipolar disorder: a proton magnetic resonance spectroscopy study of the anterior cingulate cortex," Journal of Affective Disorders, vol. 99, no. 1-3, pp. 19-25, 2007.

[41] D. L. Rothman, O. A. C. Petroff, K. L. Behar, and R. H. Mattson, "Localized $1 \mathrm{H}$ NMR measurements of $\gamma$ aminobutyric acid in human brain in vivo," Proceedings of the National Academy of Sciences of the United States of America, vol. 90, no. 12, pp. 5662-5666, 1993.

[42] H. H. Tallan, S. Moore, and W. H. Stein, "N-Acetyl-L-aspartic acid in brain," The Journal of Biological Chemistry, vol. 219, no. 1, pp. 257-264, 1956.

[43] E. E. Benarroch, "N-Acetylaspartate and N-acetylaspartylglutamate: neurobiology and clinical significance," Neurology, vol. 70, no. 16, pp. 1353-1357, 2008.

[44] J. R. Moffett, B. Ross, P. Arun, C. N. Madhavarao, and A. M. A. Namboodiri, "N-Acetylaspartate in the CNS: from neurodiagnostics to neurobiology," Progress in Neurobiology, vol. 81, no. 2, pp. 89-131, 2007.

[45] G. J. Moore and M. P. Galloway, "Magnetic resonance spectroscopy: neurochemistry and treatment effects in affective disorders," Psychopharmacology Bulletin, vol. 36, no. 2, pp. 523, 2002.

[46] A. Yildiz-Yesiloglu and D. P. Ankerst, "Neurochemical alterations of the brain in bipolar disorder and their implications for pathophysiology: a systematic review of the in vivo proton magnetic resonance spectroscopy findings," Progress in Neuro-Psychopharmacology and Biological Psychiatry, vol. 30, no. 6, pp. 969-995, 2006.

[47] S. D. Friedman, W. M. Brooks, R. E. Jung et al., "Quantitative proton MRS predicts outcome after traumatic brain injury," Neurology, vol. 52, no. 7, pp. 1384-1391, 1999.

[48] L. Kwock, J. K. Smith, M. Castillo et al., "Clinical role of proton magnetic resonance spectroscopy in oncology: brain, breast, and prostate cancer," Lancet Oncology, vol. 7, no. 10, pp. 859-868, 2006.

[49] J. K. Smith, M. Castillo, and L. Kwock, "MR spectroscopy of brain tumors," Magnetic Resonance Imaging Clinics of North America, vol. 11, no. 3, pp. 415-429, 2003.

[50] Y. Rosen and R. E. Lenkinski, "Recent advances in magnetic resonance neurospectroscopy," Neurotherapeutics, vol. 4, no. 3, pp. 330-345, 2007.

[51] D. Lopez-Villegas, R. E. Lenkinski, S. L. Wehrli, W.-Z. Ho, and S. D. Douglas, "Lactate production by human monocytes/macrophages determined by proton MR spectroscopy," Magnetic Resonance in Medicine, vol. 34, no. 1, pp. 32-38, 1995. 
[52] S. K. Gujar, S. Maheshwari, I. Björkman-Burtscher, and P. C. Sundgren, "Magnetic resonance spectroscopy," Journal of Neuro-Ophthalmology, vol. 25, no. 3, pp. 217-226, 2005.

[53] S. Frangou and S. C. R. Williams, "Magnetic resonance spectroscopy in psychiatry basic principles and applications," British Medical Bulletin, vol. 52, no. 3, pp. 474-485, 1996.

[54] G. K. Radda, "Control, bioenergetics, and adaptation in health and disease: noninvasive biochemistry from nuclear magnetic resonance," FASEB Journal, vol. 6, no. 12, pp. 30323038, 1992.

[55] L. Gyulai, L. Bolinger, and J. S. Leigh Jr., "Phosphorylethanolamine-the major constituent of the phosphomonoester peak observed by ${ }^{31} \mathrm{P}-\mathrm{NMR}$ on developing dog brain," FEBS Letters, vol. 178, no. 1, pp. 137-142, 1984.

[56] T. Glonek, S. J. Kopp, and E. Kot, "P-31 nuclear magnetic resonance analysis of brain: the perchloric acid extract spectrum," Journal of Neurochemistry, vol. 39, no. 5, pp. 1210-1219, 1982.

[57] J. W. Pettegrew, S. J. Kopp, and N. J. Minshew, " ${ }^{31} \mathrm{P}$ nuclear magnetic resonance studies of phosphoglyceride metabolism in developing and degenerating brain: preliminary observations," Journal of Neuropathology and Experimental Neurology, vol. 46, no. 4, pp. 419-430, 1987.

[58] R. Reddy and M. S. Keshavan, "Phosphorus magnetic resonance spectroscopy: its utility in examining the membrane hypothesis of schizophrenia," Prostaglandins Leukotrienes and Essential Fatty Acids, vol. 69, no. 6, pp. 401-405, 2003.

[59] P. M. Kilby, N. M. Bolas, and G. K. Radda, " ${ }^{31}$ P-NMR study of brain phospholipid structures in vivo," Biochimica et Biophysica Acta, vol. 1085, no. 2, pp. 257-264, 1991.

[60] S. Morikawa, T. Inubushi, K. Kitoh, C. Kido, and M. Nozaki, "Chemical assessment of phospholipid and phosphoenergetic metabolites in regenerating rat liver measured by in vivo and in vitro ${ }^{31} \mathrm{P}-\mathrm{NMR}, "$ Biochimica et Biophysica Acta, vol. 1117, no. 3, pp. 251-257, 1992.

[61] O. A. Petroff, J. W. Prichard, K. L. Behar, J. R. Alger, J. A. den Hollander, and R. G. Shulman, "Cerebral intracellular $\mathrm{pH}$ by $31 \mathrm{P}$ nuclear magnetic resonance spectroscopy," Neurology, vol. 35, no. 6, pp. 781-788, 1985.

[62] M. Erecinska and I. A. Silver, "ATP and brain function," Journal of Cerebral Blood Flow and Metabolism, vol. 9, no. 1, pp. 2-19, 1989.

[63] P. F. Renshaw, A. M. Parow, F. Hirashima et al., "Multinuclear magnetic resonance spectroscopy studies of brain purines in major depression," American Journal of Psychiatry, vol. 158, no. 12, pp. 2048-2055, 2001.

[64] F. G. Webb, N. Sailasuta, S. J. Kohler, T. Raidy, R. A. Moats, and R. E. Hurd, "Automated single-voxel proton MRS: technical development and multisite verification," Magnetic Resonance in Medicine, vol. 31, no. 4, pp. 365-373, 1994.

[65] J. Alvarez-Linera, "3 T MRI: advances in brain imaging," European Journal of Radiology, vol. 67, no. 3, pp. 415-426, 2008.

[66] I. K. Lyoo and P. F. Renshaw, "Magnetic resonance spectroscopy: current and future applications in psychiatric research," Biological Psychiatry, vol. 51, no. 3, pp. 195-207, 2002.

[67] D. V. Iosifescu, N. R. Bolo, A. A. Nierenberg, J. E. Jensen, M. Fava, and P. F. Renshaw, "Brain bioenergetics and response to triiodothyronine augmentation in major depressive disorder," Biological Psychiatry, vol. 63, no. 12, pp. 1127-1134, 2008.
[68] C. M. Moore, J. D. Christensen, B. Lafer, M. Fava, and P. F. Renshaw, "Lower levels of nucleoside triphosphate in the basal ganglia of depressed subjects: a phosphorous-31 magnetic resonance spectroscopy study," American Journal of Psychiatry, vol. 154, no. 1, pp. 116-118, 1997.

[69] H.-P. Volz, R. Rzanny, S. Riehemann et al., " ${ }^{31} \mathrm{P}$ magnetic resonance spectroscopy in the frontal lobe of major depressed patients," European Archives of Psychiatry and Clinical Neuroscience, vol. 248, no. 6, pp. 289-295, 1998.

[70] M. M. Chaumeil, J. Valette, M. Guillermier et al., "Multimodal neuroimaging provides a highly consistent picture of energy metabolism, validating ${ }^{31} \mathrm{P}$ MRS for measuring brain ATP synthesis," Proceedings of the National Academy of Sciences of the United States of America, vol. 106, no. 10, pp. 3988-3993, 2009.

[71] R. C. Kessler, P. Berglund, O. Demler, R. Jin, K. R. Merikangas, and E. E. Walters, "Lifetime prevalence and age-of-onset distributions of DSM-IV disorders in the national comorbidity survey replication," Archives of General Psychiatry, vol. 62, no. 6, pp. 593-602, 2005.

[72] R. H. Belmaker, "Bipolar disorder," New England Journal of Medicine, vol. 351, no. 5, pp. 476-518, 2004.

[73] J. J. Mann, “The medical management of depression," New England Journal of Medicine, vol. 353, no. 17, pp. 1819-1834, 2005.

[74] R. J. Steingard, D. A. Yurgelun-Todd, J. Hennen et al., "Increased orbitofrontal cortex levels of choline in depressed adolescents as detected by in vivo proton magnetic resonance spectroscopy," Biological Psychiatry, vol. 48, no. 11, pp. 10531061, 2000.

[75] V. Kusumakar, F. P. MacMaster, L. Gates, S. J. Sparkes, and S. C. Khan, "Left medial temporal cytosolic choline in early onset depression," Canadian Journal of Psychiatry, vol. 46, no. 10, pp. 959-964, 2001.

[76] T. R. Farchione, G. J. Moore, and D. R. Rosenberg, "Proton magnetic resonance spectroscopic imaging in pediatric major depression," Biological Psychiatry, vol. 52, no. 2, pp. 86-92, 2002.

[77] E. A. Smith, A. Russell, E. Lorch et al., "Increased medial thalamic choline found in pediatric patients with obsessive-compulsive disorder versus major depression or healthy control subjects: a magnetic resonance spectroscopy study," Biological Psychiatry, vol. 54, no. 12, pp. 1399-1405, 2003.

[78] J. C. Soares, K. R. R. Krishnan, and M. S. Keshavan, "Nuclear magnetic resonance spectroscopy: new insights into the pathophysiology of mood disorders," Depression, vol. 4, no. 1, pp. 14-30, 1996.

[79] S.-T. Hong, C.-B. Choi, C. Park et al., "Variation of the choline signal intensity in the dorsolateral prefrontal cortex of rats exposed to the forced swimming test as detected by in vivo 1H MR spectroscopy," Journal of Neuroscience Methods, vol. 165, no. 1, pp. 89-94, 2007.

[80] Y. Mirza, J. Tang, A. Russell et al., "Reduced anterior cingulate cortex glutamatergic concentrations in childhood major depression," Journal of the American Academy of Child and Adolescent Psychiatry, vol. 43, no. 3, pp. 341-348, 2004.

[81] D. R. Rosenberg, Y. Mirza, A. Russell et al., "Reduced anterior cingulate glutamatergic concentrations in childhood OCD and major depression versus healthy controls," Journal of the American Academy of Child and Adolescent Psychiatry, vol. 43, no. 9, pp. 1146-1153, 2004. 
[82] D. R. Rosenberg, F. P. MacMaster, Y. Mirza et al., "Reduced anterior cingulate glutamate in pediatric major depression: a magnetic resonance spectroscopy study," Biological Psychiatry, vol. 58, no. 9, pp. 700-704, 2005.

[83] S. C. Caetano, M. Fonseca, R. L. Olvera et al., "Proton spectroscopy study of the left dorsolateral prefrontal cortex in pediatric depressed patients," Neuroscience Letters, vol. 384, no. 3, pp. 321-326, 2005.

[84] F. P. MacMaster and V. Kusumakar, "Choline in pediatric depression,” McGill Journal of Medicine, vol. 9, no. 1, pp. 2427, 2006.

[85] Y. Mirza, J. O’Neill, E. A. Smith et al., "Increased medial thalamic creatine- phosphocreatine found by proton magnetic resonance spectroscopy in children with obsessivecompulsive disorder versus major depression and healthy controls," Journal of Child Neurology, vol. 21, no. 2, pp. 106$111,2006$.

[86] V. Gabbay, D. A. Hess, S. Liu, J. S. Babb, R. G. Klein, and O. Gonen, "Lateralized caudate metabolic abnormalities in adolescent major depressive disorder: a proton MR spectroscopy study," American Journal of Psychiatry, vol. 164, no. 12, pp. 1881-1889, 2007.

[87] F. P. MacMaster, G. J. Moore, A. Russell et al., "Medial temporal N-acetyl-aspartate in pediatric major depression," Psychiatry Research, vol. 164, no. 1, pp. 86-89, 2008.

[88] V. Gabbay, R. G. Klein, C. M. Alonso et al., "Immune system dysregulation in adolescent major depressive disorder," Journal of Affective Disorders, vol. 115, no. 1-2, pp. 177-182, 2009.

[89] V. Gabbay, L. Liebes, Y. Katz et al., "The kynurenine pathway in adolescent depression: preliminary findings from a proton MR spectroscopy study," Progress in NeuroPsychopharmacology and Biological Psychiatry, vol. 34, no. 1, pp. 37-44, 2009.

[90] P. M. Lewinsohn, P. Rohde, J. R. Seeley, D. N. Klein, and I. H. Gotlib, "Natural course of adolescent major depressive disorder in a community sample: predictors of recurrence in young adults," American Journal of Psychiatry, vol. 157, no. 10, pp. 1584-1591, 2000.

[91] R. L. Hendren, I. De Backer, and G. J. Pandina, "Review of neuroimaging studies of child and adolescent psychiatric disorders from the past 10 years," Journal of the American Academy of Child and Adolescent Psychiatry, vol. 39, no. 7, pp. 815-828, 2000.

[92] D. J. Kupfer, M. B. First, and D. A. Regier, A Research Agenda for DSM-V, American Psychiatric Publishing, Washington, DC, USA, 1st edition, 2002.

[93] M. L. Phillips and E. Frank, "Redefining bipolar disorder: toward DSM-V," American Journal of Psychiatry, vol. 163, no. 7, pp. 1135-1136, 2006.

[94] J. A. Stanley, "In vivo magnetic resonance spectroscopy and its application to neuropsychiatric disorders," Canadian Journal of Psychiatry, vol. 47, no. 4, pp. 315-326, 2002.

[95] E. Fuchs, B. Czéh, M. H. P. Kole, T. Michaelis, and P. J. Lucassen, "Alterations of neuroplasticity in depression: the hippocampus and beyond," European Neuropsychopharmacology, vol. 14, supplement 5, pp. S481-S490, 2004.

[96] A. S. Gonul, O. Kitis, E. Ozan et al., "The effect of antidepressant treatment on $\mathrm{N}$-acetyl aspartate levels of medial frontal cortex in drug-free depressed patients," Progress in NeuroPsychopharmacology and Biological Psychiatry, vol. 30, no. 1, pp. 120-125, 2006.
[97] B. P. Forester, D. G. Harper, J. E. Jensen et al., " 31 Phosphorus magnetic resonance spectroscopy study of tissue specific changes in high energy phosphates before and after sertraline treatment of geriatric depression," International Journal of Geriatric Psychiatry, vol. 24, no. 8, pp. 788-797, 2009.

[98] G. F. Mason and J. H. Krystal, "MR spectroscopy: its potential role for drug development for the treatment of psychiatric diseases," NMR in Biomedicine, vol. 19, no. 6, pp. 690-701, 2006.

[99] H. C. Kraemer, G. T. Wilson, C. G. Fairburn, and W. S. Agras, "Mediators and moderators of treatment effects in randomized clinical trials," Archives of General Psychiatry, vol. 59, no. 10, pp. 877-883, 2002.

[100] P. F. Renshaw, B. Lafer, S. M. Babb et al., "Basal ganglia choline levels in depression and response to fluoxetine treatment: an in vivo proton magnetic resonance spectroscopy study," Biological Psychiatry, vol. 41, no. 8, pp. 837-843, 1997.

[101] C. Stork and P. F. Renshaw, "Mitochondrial dysfunction in bipolar disorder: evidence from magnetic resonance spectroscopy research," Molecular Psychiatry, vol. 10, no. 10, pp. 900-919, 2005.

[102] J. E. Jensen, M. Daniels, C. Haws et al., "Triacetyluridine (TAU) decreases depressive symptoms and increases brain $\mathrm{pH}$ in bipolar patients," Experimental and Clinical Psychopharmacology, vol. 16, no. 3, pp. 199-206, 2008.

[103] P. F. Renshaw and I. K. Lyoo, "Creatine Augmentation Treatment in Major Depressive Disorder Subjects," US National Library of Medicine, Bethesda, Md, USA, http://clinicaltrials.gov/ct2/show/NCT00729755.

[104] W. A. Carlezon Jr., A. M. Pliakas, A. M. Parow, M. J. Detke, B. M. Cohen, and P. F. Renshaw, "Antidepressant-like effects of cytidine in the forced swim test in rats," Biological Psychiatry, vol. 51, no. 11, pp. 882-889, 2002.

[105] W. A. Carlezon Jr., S. D. Mague, A. M. Parow, A. L. Stoll, B. M. Cohen, and P. F. Renshaw, "Antidepressant-like effects of uridine and omega-3 fatty acids are potentiated by combined treatment in rats," Biological Psychiatry, vol. 57, no. 4, pp. 343-350, 2005.

[106] P. J. Allen, K. E. D’Anci, P. F. Renshaw, and R. B. Kararek, Dietary Creatine Supplementation: A New Model of Depression? Society for Neuroscience, Washington, DC, USA, 2008.

[107] P. J. Allen, K. E. D’Anci, R. B. Kanarek, and P. F. Renshaw, "Chronic creatine supplementation alters depression-like behavior in rodents in a sex-dependent manner," Neuropsychopharmacology, vol. 35, pp. 534-546, 2009.

[108] T. Kato and N. Kato, "Mitochondrial dysfunction in bipolar disorder," Bipolar Disorders, vol. 2, no. 3, pp. 180-190, 2000.

[109] D. V. Iosifescu and P. F. Renshaw, " ${ }^{31}$ P-Magnetic resonance spectroscopy and thyroid hormones in major depressive disorder: toward a bioenergetic mechanism in depression?" Harvard Review of Psychiatry, vol. 11, no. 2, pp. 51-63, 2003.

[110] T. Kato, "Mitochondrial dysfunction as the molecular basis of bipolar disorder: therapeutic implications," CNS Drugs, vol. 21, no. 1, pp. 1-11, 2007.

[111] L. Shao, M. V. Martin, S. J. Watson et al., "Mitochondrial involvement in psychiatric disorders," Annals of Medicine, vol. 40, no. 4, pp. 281-295, 2008.

[112] K. Chang, N. Adleman, C. Wagner, N. Barnea-Goraly, and A. Garrett, "Will neuroimaging ever be used to diagnose pediatric bipolar disorder?" Development and Psychopathology, vol. 18, no. 4, pp. 1133-1146, 2006. 
[113] Y. Goto, C. R. Yang, and S. Otani, "Functional and dysfunctional synaptic plasticity in prefrontal cortex: roles in psychiatric disorders," Biological Psychiatry, vol. 67, no. 3, pp. 199-207, 2009.

[114] H. K. Manji, J. A. Quiroz, J. Sporn et al., "Enhancing neuronal plasticity and cellular resilience to develop novel, improved therapeutics for difficult-to-treat depression," Biological Psychiatry, vol. 53, no. 8, pp. 707-742, 2003.

[115] S. J. Mathew, H. K. Manji, and D. S. Charney, "Novel drugs and therapeutic targets for severe mood disorders," Neuropsychopharmacology, vol. 33, no. 9, pp. 2080-2092, 2008.

[116] P. J. Carlson, J. B. Singh, C. A. Zarate Jr., W. C. Drevets, and H. K. Manji, "Neural circuitry and neuroplasticity in mood disorders: insights for novel therapeutic targets," NeuroRx, vol. 3, no. 1, pp. 22-41, 2006.

[117] H. K. Manji, W. C. Drevets, and D. S. Charney, "The cellular neurobiology of depression," Nature Medicine, vol. 7, no. 5, pp. 541-547, 2001.

[118] R. S. Duman, G. R. Heninger, and E. J. Nestler, "A molecular and cellular theory of depression," Archives of General Psychiatry, vol. 54, no. 7, pp. 597-606, 1997.

[119] G. Sanacora, G. F. Mason, D. L. Rothman et al., "Reduced cortical $\gamma$-aminobutyric acid levels in depressed patients determined by proton magnetic resonance spectroscopy," Archives of General Psychiatry, vol. 56, no. 11, pp. 1043-1047, 1999.

[120] T. A. Klempan, A. Sequeira, L. Canetti et al., "Altered expression of genes involved in ATP biosynthesis and GABAergic neurotransmission in the ventral prefrontal cortex of suicides with and without major depression," Molecular Psychiatry, vol. 14, no. 2, pp. 175-189, 2009.

[121] G. Rajkowska, G. O’Dwyer, Z. Teleki, C. A. Stockmeier, and J. J. Miguel-Hidalgo, "GABAergic neurons immunoreactive for calcium binding proteins are reduced in the prefrontal cortex in major depression," Neuropsychopharmacology, vol. 32, no. 2, pp. 471-482, 2007.

[122] G. Sanacora and A. Saricicek, "GABAergic contributions to the pathophysiology of depression and the mechanism of antidepressant action," CNS and Neurological Disorders, vol. 6, no. 2, pp. 127-140, 2007.

[123] G. Sanacora, R. Gueorguieva, C. N. Epperson et al., "Subtype-specific alterations of $\gamma$-aminobutyric acid and glutamate in patients with major depression," Archives of General Psychiatry, vol. 61, no. 7, pp. 705-713, 2004.

[124] D. A. Yurgelun-Todd, S. Sava, and M. K. Dahlgren, "Mood Disorders," Neuroimaging Clinics of North America, vol. 17, no. 4, pp. 511-521, 2007.

[125] A. J. Gerber and B. S. Peterson, "What is an image?" Journal of the American Academy of Child and Adolescent Psychiatry, vol. 47, no. 3, pp. 245-248, 2008.

[126] H. S. Mayberg, "Limbic-cortical dysregulation: a proposed model of depression," Journal of Neuropsychiatry and Clinical Neurosciences, vol. 9, no. 3, pp. 471-481, 1997.

[127] P. Davanzo, K. Yue, M. A. Thomas et al., "Proton magnetic resonance spectroscopy of bipolar disorder versus intermittent explosive disorder in children and adolescents," American Journal of Psychiatry, vol. 160, no. 8, pp. 1442-1452, 2003.

[128] C. M. Moore, J. Biederman, J. Wozniak et al., "Differences in brain chemistry in children and adolescents with attention deficit hyperactivity disorder with and without comorbid bipolar disorder: a proton magnetic resonance spectroscopy study," American Journal of Psychiatry, vol. 163, no. 2, pp. 316-318, 2006.
[129] N. Carrey, F. P. MacMaster, J. Fogel et al., "Metabolite changes resulting from treatment in children with ADHD: a 1H-MRS study," Clinical Neuropharmacology, vol. 26, no. 4, pp. 218-221, 2003.

[130] N. Carrey, F. P. MacMaster, S. J. Sparkes, S. C. Khan, and V. Kusumakar, "Glutamatergic changes with treatment in attention deficit hyperactivity disorder: a preliminary case series," Journal of Child and Adolescent Psychopharmacology, vol. 12, no. 4, pp. 331-336, 2002.

[131] P. A. Bottomley, "The trouble with spectroscopy papers," Radiology, vol. 181, no. 2, pp. 344-350, 1991.

[132] R. Kreis, "Issues of spectral quality in clinical 1H-magnetic resonance spectroscopy and a gallery of artifacts," NMR in Biomedicine, vol. 17, no. 6, pp. 361-381, 2004.

[133] J. S. Taylor, "The trouble with spectroscopy papers, 15 years later," NMR in Biomedicine, vol. 19, no. 4, pp. 409-410, 2006.

[134] A. R. Tate, J. Underwood, D. M. Acosta et al., "Development of a decision support system for diagnosis and grading of brain tumours using in vivo magnetic resonance single voxel spectra," NMR in Biomedicine, vol. 19, no. 4, pp. 411-434, 2006.

[135] M. van der Graaf, M. Julià-Sapé, F. A. Howe et al., "MRS quality assessment in a multicentre study on MRS-based classification of brain tumours," NMR in Biomedicine, vol. 21, no. 2, pp. 148-158, 2008.

[136] J. M. Garcia-Gomez, J. Luts, M. Julia-Sape et al., "Multiproject-multicenter evaluation of automatic brain tumor classification by magnetic resonance spectroscopy," Magnetic Resonance Materials in Physics, Biology and Medicine, vol. 22, no. 1, pp. 5-18, 2009.

[137] T. Kato, S. Takahashi, T. Shioiri, and T. Inubushi, "Brain phosphorous metabolism in depressive disorders detected by phosphorus-31 magnetic resonance spectroscopy," Journal of Affective Disorders, vol. 26, no. 4, pp. 223-230, 1992.

[138] P. Davanzo, M. A. Thomas, K. Yue et al., "Decreased anterior cingulate myo-inositol/creatine spectroscopy resonance with lithium treatment in children with bipolar disorder," Neuropsychopharmacology, vol. 24, no. 4, pp. 359-369, 2001.

[139] M. P. DelBello, K. M. Cecil, C. M. Adler, J. P. Daniels, and S. M. Strakowski, "Neurochemical effects of olanzapine in first-hospitalization manic adolescents: a proton magnetic resonance spectroscopy study," Neuropsychopharmacology, vol. 31, no. 6, pp. 1264-1273, 2006.

[140] N. C. Patel, M. P. DelBello, K. M. Cecil et al., "Lithium treatment effects on myo-inositol in adolescents with bipolar depression," Biological Psychiatry, vol. 60, no. 9, pp. 998-1004, 2006.

[141] N. C. Patel, M. P. DelBello, K. M. Cecil, K. E. Stanford, C. M. Adler, and S. M. Strakowski, "Temporal change in N-acetylaspartate concentrations in adolescents with bipolar depression treated with lithium," Journal of Child and Adolescent Psychopharmacology, vol. 18, no. 2, pp. 132-139, 2008.

[142] K. Chang, A. Karchemskiy, R. Kelley et al., "Effect of divalproex on brain morphometry, chemistry, and function in youth at high-risk for bipolar disorder: a pilot study," Journal of Child and Adolescent Psychopharmacology, vol. 19, no. 1, pp. 51-59, 2009.

[143] D. P. Dickstein, K. E. Towbin, J. W. Van Der Veen et al., "Randomized double-blind placebo-controlled trial of lithium in youths with severe mood dysregulation," Journal of Child and Adolescent Psychopharmacology, vol. 19, no. 1, pp. 61-73, 2009. 


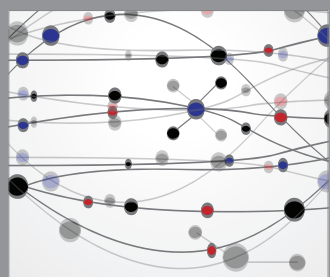

The Scientific World Journal
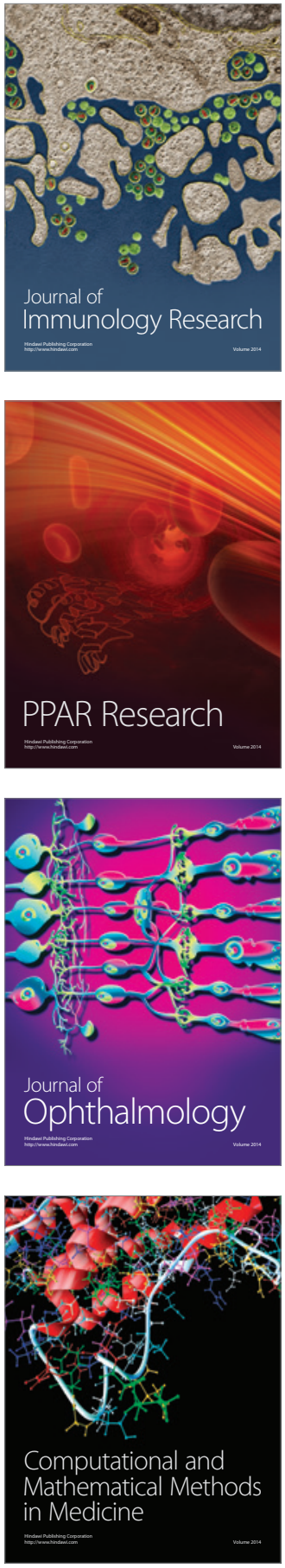

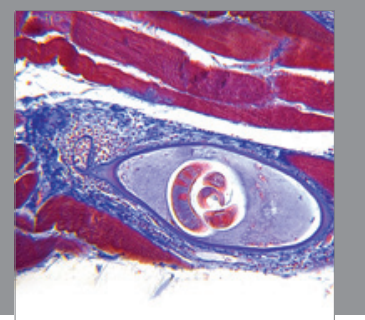

Gastroenterology

Research and Practice
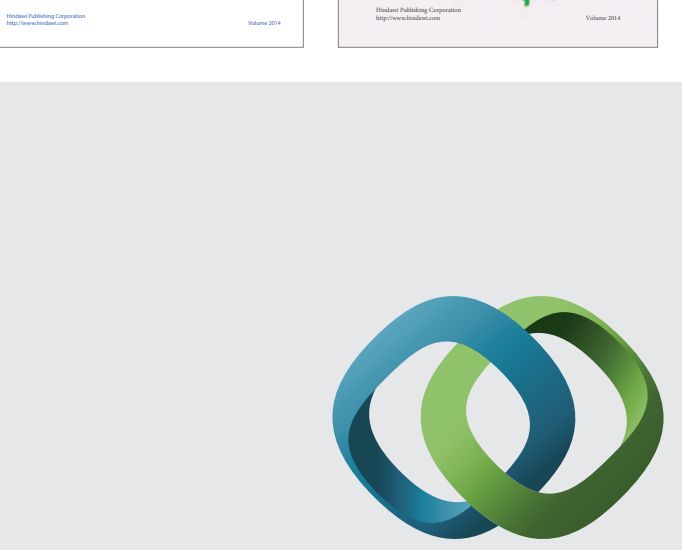

\section{Hindawi}

Submit your manuscripts at

http://www.hindawi.com
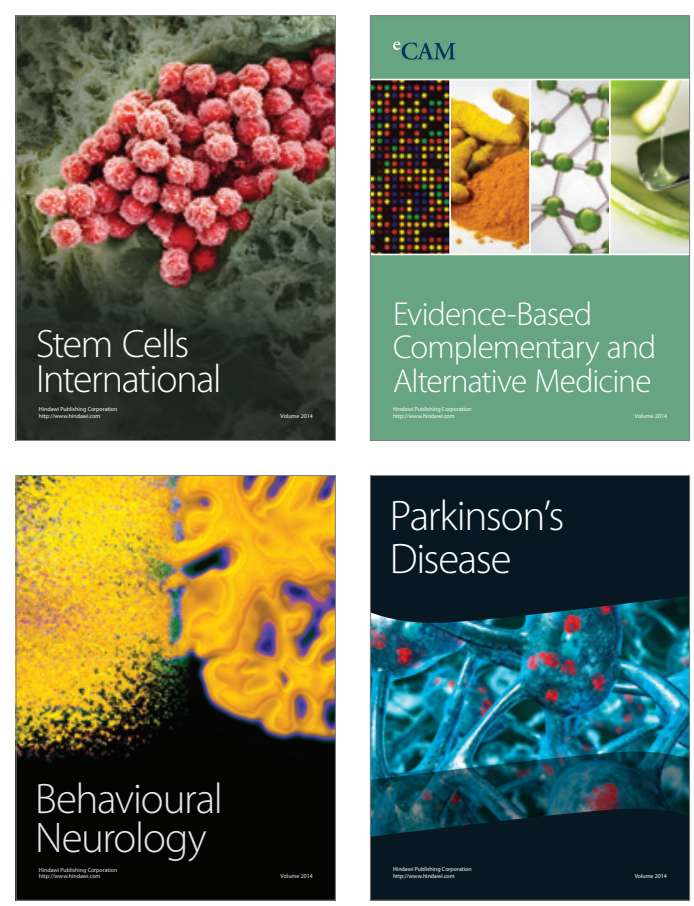

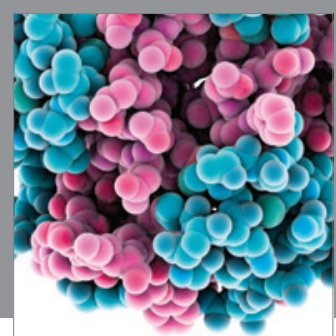

Journal of
Diabetes Research

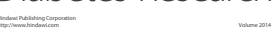

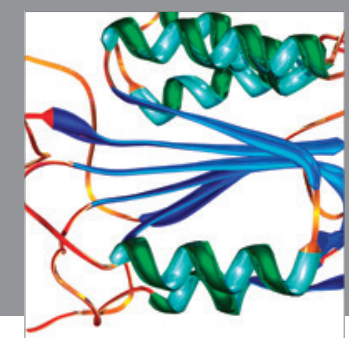

Disease Markers
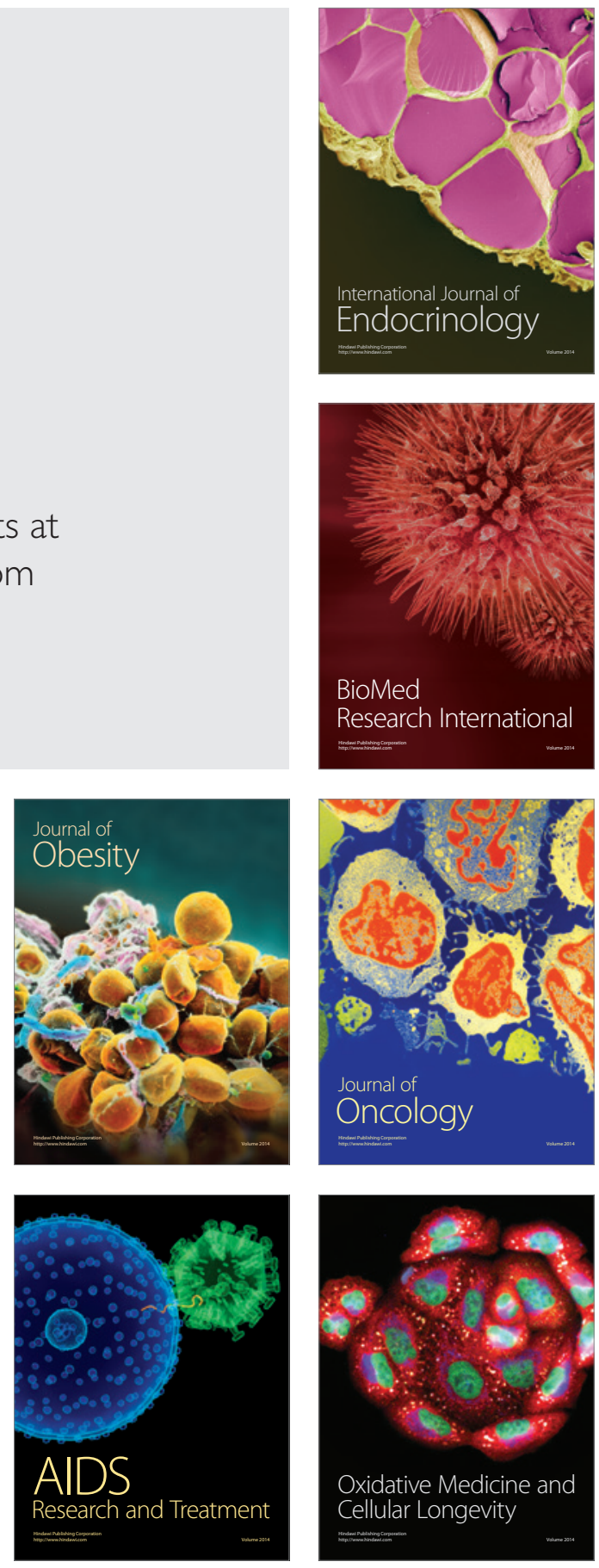